\title{
Paulo Freire e Papa Francisco: Diálogo sobre discernimento e educação ecológica na Laudato Si’
}

\author{
Paulo Freire and Papa Francisco: Dialogue on discernment
}

and ecological education at Laudato Si'

AlLAN DA Silva Coelho (ida

\section{Resumo}

Na reflexão sobre a Encíclica Laudato Si', estabelecemos um diálogo entre a Pedagogia do Oprimido, de Paulo Freire, e a proposta de um itinerário pedagógico do Papa Francisco. A partir da metodologia dialética goldminiana, defendemos que a transição ecológica da Laudato Si' explicita elementos de uma educação antifetichista (com afinidades aos estudos do "capitalismo como religião") que permitiriam outros modelos de humanidade.

Palavras-chave: Itinerário pedagógico. Modelos de humanidade. Transição ecológica. Fetichismo.

\section{Abstract}

In the reflection on the Encyclical Laudato Si', a dialogue is established between the Pedagogy of the Oppressed, by Paulo Freire, and the proposal of a pedagogical itinerary by Pope Francis. From the goldminian dialectical methodology, we defend that the ecological transition of Laudato Símakes explicit elements of an anti-fetishistic education, (with affinities to the studies of "capitalism as religion") that would allow other models of humanity.

Keywords: Pedagogical itinerary. Models of humanity. Ecological transition. Fetishism.

\footnotetext{
a Universidade São Francisco (USF), Bragança Paulista, SP, Brasil. Doutor em Ciências da Religião, e-mail: allan.filos@gmail.com
} 


\section{Introdução}

Paulo Freire, grande educador de nossa América Latina, dizia em sua obra magna Pedagogia do Oprimido que a humanidade, desafiada pela "dramaticidade da hora atual", descobre-se como problema, a refletir e buscar respostas para transformar a realidade a partir de suas contradições. Ele discutia o final dos anos 1960, em que rebeliões se espalhavam mundo afora para contestar uma ordem mundial que Freire caracterizou pela "cultura de consumo" (FREIRE, 2014, p. 39) e amplos movimentos sociais se empenhavam em construir modelos alternativos ao sistema social, nos quais expressava-se claramente o problema da humanização: apesar da vocação ontológica a ser mais, ser gente, as pessoas têm, na realidade histórica de desumanização, a sua humanidade roubada.

Essas páginas de Paulo Freire servem de instrumental para pensar a relação entre educação e ecologia. Nosso olhar procura perceber que elementos presentes na Encíclica Laudato Si', relacionados à nossa pedagogia latino-americana, podem colaborar nos processos de transição ecológica, articulando a análise da realidade, um julgamento ético-teológico e o necessário engajamento por modificar as condições sociais que geram vítimas cotidianas.

Na Laudato Si', o tema da ecologia foi elevado ao ápice do magistério eclesial católico em uma profunda inovação de perspectivas da doutrina social cristã (LÖWY, 2017). O Papa Francisco expressa um apelo de urgência em que associa um diagnóstico da realidade com a indicação de caminhos a serem percorridos.

Nessa reflexão, vamos nos dedicar a como a proposta de Francisco de um “itinerário pedagógico" permite pensar elementos para uma educação antifetichista, que colabore no processo de conversão ecológica na medida em que discernimos entre os deuses que estão em luta pela hegemonia em nosso sistema social'. Na primeira parte refletimos sobre o contexto a partir do qual

\footnotetext{
${ }^{1}$ As reflexões do âmbito da Filosofia da Educação no campo de estudos do "capitalismo como religião" indicam a necessidade de identificar os elementos de uma educação antifetichista para a superação do sistema social em vigor. Esses estudos tem como 
pensamos (ver), para em seguida analisar os critérios da crítica (julgar) e tatear as possibilidades para uma ação pedagógica radicalmente comprometida com a vida (agir) ${ }^{2}$.

\section{A vida em um sistema social marcado pela morte}

A dramaticidade da hora atual nos interpela. Além da contradição entre a vocação a ser mais e a vida cotidiana de exploração e negação da dignidade humana, precisamos indicar outras duas contradições associadas que dificultam encontrar uma saída para este drama. Se por um lado cada vez mais pessoas estão insatisfeitas com a vida que se tem, por outro lado, ao invés de interromper o sistema que desumaniza, as pessoas tentam com todas as forças se integrar ao sistema a partir dos seus critérios de sucesso, de reconhecimento e de felicidade almejada pelo consumo de mercadorias.

Esta contradição, que reforça o sistema social ao invés de questioná-lo, leva ao aumento exponencial da autoexploração com o objetivo de se conquistar, no mercado, a "vida digna" que se deseja, como sinal de mérito. Isso se dá porque, segundo Paulo Freire (2014), o modelo de ser mais, de humanidade que todos nós temos, ainda é o opressor. Portanto, para a imensa maioria das pessoas, deixar a condição de desumanidade supõe não a transformação de um sistema social que condena poucos à riqueza e multidões à exclusão, mas a inversão de seu papel pessoal nesse sistema, de pobre a tornar-se o rico bem-aventurado por ser bem-sucedido no mercado. Esse é o contexto de fundo com o qual a Encíclica Laudato Si' nos permite pensar a educação.

Esta reflexão situa-se historicamente a partir do Brasil sob a violência de duas grandes expressões dos perigos de nossa época: a pandemia do coronavírus e a ameaça neofascista da extrema direita. Ambos expõem a crueldade de uma sociedade com radical diferença de condições de vida.

referência o diálogo entre a tradição de Walter Benjamin (2013) e o cristianismo de libertação, como indica Michael Löwy (2016).

${ }^{2}$ Esse texto apresenta os resultados parciais de nossa pesquisa junto à CLACSO - GT "El futuro del trabajo y el cuidado con la casa comun". 
Frente aos milhares de mortos pela crise sanitária ${ }^{3}$, temos uma defesa da indiferença, do falacioso valor da economia sobre a vida humana e o acirramento das políticas neoliberais que precarizam as condições de trabalho, retiram direitos sociais básicos e atuam para a devastação do meio ambiente, o fim dos direitos de povos originários e quilombolas, a eliminação do pouco conquistado em relação à igualdade de gênero ou racial.

A crise sanitária é compreendida como uma "oportunidade" para aprofundar a privatização e o desmonte do Estado e de garantias constitucionais de direitos. Uma ideologia de defesa da morte e da agressividade destrutiva do outro e do planeta como projeto de vida que seduz parcela significativa da população e com forte apoio dos cristãos. Nesse sentido, o Brasil é um dos exemplares novos laboratórios de um fundamentalismo neoliberal que articula economia e maneira de viver ${ }^{4}$.

Entretanto, se incluirmos essa realidade local no conjunto da América Latina ou do mundo globalizado, percebemos que não se trata nem de um caso isolado, nem mesmo de um anacronismo ou erro no percurso do desenvolvimento civilizatório: parece que a ordem mundial aposta a sobrevivência do sistema econômico com esse projeto que radicaliza, entre outros, a ideologia da destruição do outro/diferente como necessária; a promessa mítico-teológica de que uma vida melhor vem somente com grandes sacrifícios/sofrimento e, ainda, a violência como estratégia para o novo.

Estamos diante de uma convergência de crises, que inclui crise sanitária, econômica, migratória, do trabalho, além da climática... que segundo o Papa Francisco, não se pode "analisar nem explicar de forma isolada" (Laudato Si' LS, n. 61), pois temos ante nós uma única e complexa crise (LS, n. 139). Essa convergência de crises tem como consequência imediata milhares de mortes reais, concretas, contáveis... mas também produz variadas formas de violência e vitimação de boa parte da humanidade, sendo especialmente cruel com os mais pobres.

\footnotetext{
${ }^{3}$ Neste momento, temos no coração dolorido a marca de 500 mil mortos como vítimas diretas e registradas do coronavírus, de um total estimado de 3,8 milhões de vítimas no mundo.

${ }^{4}$ Sobre as relações entre essa ideologia econômica e um marco de compreensão teológico sacrificial: COELHO, 2021.
} 
No entanto, seus efeitos nefastos não se limitam aos visivelmente atingidos. Todos, de certo modo, são atingidos pelos efeitos da crise socioecológica, seja pelos efeitos nas condições climáticas sobre todos, seja pelo impacto da vida geral pervertida de sentido na sociedade capitalista em que produzir, consumir e descartar configuram a aposta na qual a imensa maioria dedica a sua vida.

Desse modo, desenha-se um modelo antropológico em que o consumo se torna um diferenciador social (SUNG, 2015) e critério de avaliação do sucesso. O brilho das mercadorias gesta um fascínio que seduz e mobiliza, organizando os sentidos da vida das pessoas dentro do mercado. Na cultura de consumo, a posse de bens e mercadorias oferece a promessa de prazer e felicidade, de realização humana, mas, no entanto, distribui generosamente frustração e repressão, convertendo sua promessa em agressividade e maior exploração (COELHO, 2021). Esse fascínio tem o poder de convocar para uma competição infinita, na qual a maior parte das pessoas humanas não se sente realizada jamais.

O Papa Francisco caracteriza esse sistema econômico e social com muita clareza5 . Os poderes econômicos, na especulação em busca de lucro, ignoram os efeitos de degradação ambiental e humana (LS, n.56). Trata-se de um sistema que salva bancos, mas não salva as vidas. Impõe os custos do resgate do sistema financeiro a toda a população, mas não reflete sobre os limites do próprio sistema. O princípio maior do mercado, maximizar os lucros e minimizar os custos, seria uma “distorção conceitual da economia" (LS, n. 195). Apoia-se numa concepção mágica do mercado que acredita que o lucro resolve tudo. Coloca as finanças acima do futuro de todos. É ganancioso, irresponsável, imediatista e insustentável, mas considera quem o critica como irracional.

Esse sistema não é apto para promover a defesa da vida, não é capaz de salvar nem a vida dos pobres, nem o ambiente. A lógica que organiza o sistema não permite compreender os ritmos da natureza, seus tempos de regeneração, nem a complexidade dos ecossistemas. Pensa a natureza como um reservatório à disposição. Nesse sentido, não basta conciliar a meio-termo

\footnotetext{
${ }^{5}$ Abordamos com maior detalhe esse tema em COELHO, 2018.
} 
o ganho financeiro com a preservação ambiental, pois seria "apenas um pequeno adiamento do colapso." É preciso, de fato, "redefinir o progresso" (LS, n. 194).

Nessa dura caracterização do sistema econômico, há uma interessante conexão com o vocabulário e o horizonte de compreensão desenvolvido pela Teologia latino-americana, em especial no campo que estuda as relações entre a teologia e a economia na denúncia do "capitalismo como religião", seja na crítica da absolutização das instituições como o mercado, seja na crítica do fetichismo e da idolatria do dinheiro, do capital e das mercadorias (COELHO, 2019). Vale registrar que seria interessante perceber o quanto a crítica do conceito de progresso tem de proximidade com a crítica de Walter Benjamin em sua famosa Tese IX "Sobre o Conceito de História" (LÖWY, 2005). No entanto, nos marcos de nossa reflexão, destacamos que, se o Papa caracteriza como problemática a própria concepção econômica do sistema, essa lógica implica consequências negativas para o modo de viver que nele se organiza. Trata-se de um estilo de vida no qual a lógica econômica de produção e consumo de mercadorias torna-se seu fundamento cultural, em que a objetificação das pessoas (reificação) e a personificação e/ou divinização das coisas (fetichismo) são levados ao extremo na vida cotidiana.

$\mathrm{Na}$ Laudato Si', Francisco classifica este modo de viver como um relativismo prático no qual "aproveita-se do outro como se fosse objeto" (LS, n. 123). Em variações, pode se expressar pela perversa lógica de utilizar as pessoas e descartá-las ou mesmo no aproveitar-se de um irmão em condições de vulnerabilidade, em vistas a ser mais bem sucedido na concorrência. Também se expressa na indiferença frente o desastre social e climático, mas principalmente, na captura dos desejos humanos, moldando-os ao consumo desordenado de consumir, compulsivo e obsessivo, que faz nos pensar livres, mas na verdade nos entorpece (LS, n. 203 e 223).

Não só tem a premissa do consumo desnecessário, excessivo e acumulativo, mas também produz danos inevitáveis à vida de todos e à natureza, com a consequente geração de resíduos e descartáveis, naturalizando a prática do “jogar fora”, seja de produtos, seja de outros seres humanos, em especial dos mais frágeis. 
Um detalhe curioso é que, mesmo com precisão de detalhes na crítica, a palavra capitalismo não aparece na Encíclica Laudato Si'. Francisco prefere “descrever" o sistema. Emilce Cuda afirma que esse sistema, ao longo da "modernidad ha tomado distintos nombres como capitalismo, neoliberalismo, libertarianismo, explotación, efecto cascada, progreso, sustentabilidad. El Papa Francisco lo denomina simplemente 'sistema', y algunos de sus críticos dicen no comprender de qué habla cuando habla de sistema" (CUDA, 2018, p. 256). Como parece evidente, a descrição não deixa dúvidas: trata-se do capitalismo, caracterizado em suas versões contemporâneas.

Francisco afirma que a crise econômica de 2008 foi uma ocasião que deveria levar a um outro modelo econômico de economia, mas não houve reação (LS, n.189). Que seria necessário para modificar a maneira de pensar e viver? O site francês de jornalismo investigativo Mediapart publicou uma reportagem em que avalia o impacto de uma epidemia mundial como a de Covid-19 na gestação de alternativas de transição ecológica. A matéria assinada por Amèlie Poinssot (2021) afirma que a epidemia foi um "estalo", um mecanismo que aciona preocupações com o modo de vida que se leva.

Entre os casos em estudo, apontam-se as seguintes questões: a adoção de um modo de vida mais sóbrio, maior engajamento em coletivos, a busca por se instalar no campo e mesmo a mudança de emprego. Alguns, de acordo com a matéria, teriam dado uma "grande virada" na própria vida. No entanto, apesar de seu aspecto positivo e ilustrativo, parece-nos que esse fenômeno não é massivo e nem mesmo amplo o suficiente para, por enquanto, afetar o funcionamento do sistema social. O que, nas condições atuais, seria capaz de mobilizar uma grande transformação nas pessoas e no sistema social?

Em resumo, temos um cenário de convergência de crises (destacamos a crise do trabalho, econômica, migratória, sanitária e ecológica) que tem como resultado explícito de centenas de milhares de mortes reais e das mais variadas formas de vítimas. A isso, adicionamos uma vida privada de sentido em que os marcadores de realização social que prometem felicidade e prazer entregam uma sensação geral de frustração e o aumento da depressão. Temos a hegemonia de um projeto social radical que é suicida a curto prazo: mata os seres humanos e aniquila as condições naturais de vida no planeta. Se este cenário não provoca uma modificação radical no sistema social e econômico e 
em seu modo de viver, que tipo de ação colaboraria a gestar a transição ecológica necessária e urgente?

Entre as ações apontadas, mais uma vez surge o papel da educação na gestação de um outro estilo de vida. Na Encíclica Laudato Si', ao apontar um outro "estilo de vida" (LS, n. 203-208), o Papa segue a reflexão sobre como “educar para a aliança entre a humanidade e ambiente” (LS, n. 209-215), para, em seguida, discutir a necessidade de uma “conversão ecológica” (LS, n. 216221).

Após a caracterização do problema, propomos refletir de que modo a ideia de uma conversão ecológica é mais útil na compreensão do problema do que a noção de consciência ecológica. Nossa reflexão segue como referência a tradição de estudos do "capitalismo como religião" que, visando uma epistemologia divergente, incorpora a dimensão mítico-teológica ao pensamento crítico (COELHO, 2021). Em seguida, propomos pensar elementos de um itinerário educativo que colabore a provocar conversão e rebelião, na perspectiva antifetichista.

\section{Educação e Ecologia: da consciência ecológica à conversão ecológica}

De certa forma, não há nada de especial em apontar a educação como solução para um problema como esse. Quase um clichê, sempre parece desproporcional a expectativa que se coloca sobre a capacidade da escola de ensinar certas coisas que terão como resultado a transformação da maneira como o sistema econômico se organiza. No entanto, na Encíclica Laudato Si', gostaríamos de destacar dois elementos diferentes. O primeiro, uma diferente compreensão do processo de educação para além da escola e, o segundo, uma diferença na concepção de conversão.

Francisco aponta que não se trata de um processo de ensinar conteúdos que permitam uma compreensão da crise. Se antes a educação era centrada na transmissão de informações científicas sobre a crise ambiental e na busca pela conscientização, agora, a proposta de educação supõe duas outras abordagens: a crítica dos mitos da modernidade que se baseia na razão 
instrumental e um processo para predispor um outro sentido mais profundo para a vida humana.

O processo de ensinar conteúdos como transmissão de informações científicas é um dos problemas ao qual já se dedicou Paulo Freire na crítica da educação bancária, que compreende os detentores das informações corretas como sujeitos que explicam ou narram esses conteúdos àqueles que estão desprovidos da verdade. É uma compreensão tradicional, na qual o que sabe doa, comunica a partir de sua autoridade, ao educando que recebe, repete, memoriza e arquiva o que lhe foi transmitido.

No entanto, a essa crítica, também é preciso adicionar a constatação de que aquilo que se chamou de conscientização, se limitada a um convencimento ou mudança de opinião resultante de uma boa argumentação, também não resulta no processo de formar novos sujeitos, inseridos no mundo como seus transformadores (FREIRE, 2014, p.83).

Esse tipo de conscientização mantém a concepção dicotômica de formação humana como um depositar algo dentro dos homens e mulheres. É a concepção mecânica da consciência em que oferecemos slogans ecológicos, bem definidos e controlados, no lugar de enfrentar em conjunto um processo de problematização. Os melhores slogans ecológicos transmitidos podem ampliar as informações ou até mesmo modificar a mentalidade de muita gente, mas enquanto saber intelectual, puramente racional, não têm necessariamente condições suficientes de modificar a situação concreta que ameaça a vida de todos. Por isso, Paulo Freire afirma que a construção da consciência é um caminho a ser percorrido em conjunto, enquanto educadores e educandos, ao mesmo tempo em que problematizam seu conhecimento, modificam a maneira em que vivem e a sociedade que gesta a injustiça. Para isso, é preciso ir além do convencimento, é preciso uma mudança radical de paradigma, incluindo, como aponta Freire, a mudança dos "testemunhos de humanidade", os modelos a partir dos quais nós pensamos o que é a melhor vida humana e o percurso adequado para a humanização de todos.

Neste sentido, trata-se claramente de um outro estilo de vida como o apontado na Laudato Si', a partir da desconstrução dos modelos que hoje nos conduzem ao consumo, à concorrência, o imediatismo, o individualismo e a indiferença, para um estilo de vida alternativo, diferente, que, por exemplo, se 
apoie na solidariedade, na responsabilidade, no cuidado e na compaixão (LS, n. 210). É preciso uma mudança mais profunda do que aquela das ideias intelectuais, é preciso modificar os modelos de desejo, a partir de outros testemunhos de humanidade. Nesta Encíclica, Francisco apresenta como testemunho alternativo de humanidade o outro Francisco, o de Assis, como exemplo de cuidado e alegria.

Uma questão fundamental é que, historicamente, na medida em que constatamos o avanço da hegemonia do neoliberalismo, temos um proporcional recuo do horizonte da revolução nas propostas políticas concretas. A conscientização em que parte da educação regular ou popular apostou nas últimas décadas não assegurou um processo contínuo de progresso rumo à transformação social. Nesse sentido, o apontamento do Papa Francisco é importante, para evitarmos repetir processos educativos que não resultam no que esperamos: uma transformação radical da sociedade.

Por isso, na superação de mitos da modernidade baseados na razão instrumental inclui-se refletir e questionar os conceitos de individualismo, de progresso ilimitado, de concorrência, de consumismo e de mercado acima das regras (LS, n. 210). Todos estes conceitos que, articulados, constituem um quadro categorial, não são simples ideias racionais, mas organizam um horizonte de plausibilidade a partir dos quais formulamos os sentidos mais profundos, que na mesma passagem o Papa relaciona ao Mistério. Desse modo, a educação relacionada à espiritualidade, sua dimensão religiosa, supõe uma mobilização das apostas existenciais mais profundas.

Assim, parece-nos que o conceito de fetichismo permite uma chave de leitura mais complexa para os processos de transformação das pessoas e da sociedade. A consciência fetichizada perverte a vida de todos, também de cristãos e militantes sociais comprometidos. A mística do fetiche seduz para felicidade, não no âmbito das puras ideias racionais, mas nas apostas de realização.

Porém, na prática oferece frustração, agressividade e mais exploração sobre a natureza e o humano. A dominação e exploração nesse sistema econômico atinge a vida tanto na produção (trabalho) de mercadorias, com em sua distribuição (consumo), iluminados pelo brilho frágil da sedução à 
felicidade do ídolo-fetiche. Trata-se de um falso deus, que seduz e exige submissão. Por isso que não se basta um processo de conscientização, mas é necessária a conversão.

Dessa maneira, de que modo podemos pensar um itinerário pedagógico, como propõe o Papa Francisco em Laudato Si', para que mais do que uma consciência ecológica, possamos alcançar um grau radical de transformação da maneira de viver como uma conversão ecológica? Avançando um pouco mais, é possível entender a superação da lógica do fetichismo como um tipo de formação humana que, alterando seus testemunhos de humanidade e modelos de desejo, contribua na gestação de mulheres e homens novos?

Antes de avançarmos, tateando um caminho para responder a esta questão provocadora, precisamos nos deter na novidade do conceito de conversão ecológica. De certa forma, já argumentamos que as informações científicas e discursos articulados como slogans ecológicos são capazes de orientar a razão da consciência, mas não necessariamente transformam o conjunto das opções e apostas mais fundamentais das pessoas. Por isso, propor que não basta consciência ecológica, mas é necessário a conversão ecológica expressa melhor esse tipo de questão.

Entretanto, na própria Encíclica, Francisco indica que o Papa João Paulo Il já havia utilizado o tema da conversão associado à educação ecológica. Entre os exemplos, uma interessante mensagem para o XXIII Dia Mundial da Paz de 1990 na qual o Pontífice daquela época afirma que "a verdadeira educação para a responsabilidade acarreta uma autêntica conversão no modo de pensar e de se comportar" (1989). Nesta mensagem, João Paulo II afirma que o ser humano precisa se "dar conta" da gravidade da situação, expressando um problema de limites da consciência sobre o mundo. Em seguida, ao propor a conversão no modo de pensar e agir, relaciona esta conversão com um problema essencialmente moral de cada ser humano, que não reconhece a ordem divina que lhes confiou o mundo. Isso é, trata-se de um problema de fidelidade, daquele que, se conhece os desígnios de Deus, deve agir de forma coerente. Conversão como retorno, aproximação da vontade divina.

No texto do Papa Francisco, a conversão tem outro sentido geral: tratase da adesão a um outro "modelo relativo ao ser humano, à vida, à sociedade 
e à relação com a natureza" em contrapartida com a superação do atual "modelo consumista, transmitido pelos meios de comunicação social e através dos mecanismos eficazes do mercado" (LS, n. 215). Indo além, poderíamos dizer que conversão aqui supõe o discernimento do Deus do dinheiro, do mercado e da mercadoria como um fetiche, um ídolo que promete vida e redenção, mas gera morte. Desse modo, converter é reconhecer os deuses da opressão como falsos deuses e aderir com todo o coração ao Deus da vida, o Deus de Jesus. Não se trata de um problema de fidelidade a Deus, mas de fidelidade a qual Deus? Negar a divindade do ídolo-fetiche, proclamar-se ateu desses falsos valores é o primeiro passo para a conversão que é necessária ${ }^{6}$.

Essa interpretação pode ser referendada a partir da catequese proferida por Francisco na qual pede que reconheçamos e erradiquemos os ídolos, pois eles nos têm escravizados. Disse o Papa que "los ídolos esclavizan. Prometen felicidad, pero no la dan; y nos encontramos viviendo para esa cosa o esa visión, atrapados en un vórtice autodestructivo, esperando un resultado que nunca llega" (FRANCISCO, 2020).

Afirmando o tema teológico da idolatria como algo de grande atualidade pois afeta igualmente a quem professa a fé cristã ou não, continuou afirmando que o ídolo utiliza dinâmicas da publicidade e manifesta-se no automóvel, no telefone e outras coisas que entendo como "un medio para realizarme y responder a mis necesidades esenciales" (FRANCISCO, 2020). Ele acrescentou que "la idea de poseer ese objeto o realizar ese proyecto, llegar a esa posición, parece una forma maravillosa de alcanzar la felicidad, una torre para alcanzar el cielo, y todo se vuelve funcional para ese objetivo" (FRANCISCO, 2020). Porém, na prática os ídolos exigem culto, sacrifício no esforço de alcançá-los e sangue, mas oferecem apenas ruína de vidas e famílias nesta busca pelo lucro. Evidente que esse raciocínio de Francisco o insere coerentemente na tradição teológica que critica o capitalismo como religião idólatra.

\footnotetext{
6 Trabalhamos parcialmente a temática da idolatria em João Paulo II e em Francisco: COELHO, 2019.
} 
De maneira geral, nesta perspectiva, propomos uma dupla forma de compreender a categoria da idolatria/fetichismo. A primeira seria a crítica do próprio processo de fetichização e sua pressuposta violência sacrifical. Articulam-se três dimensões: (a) a absolutização de qualquer coisa criada pela ação humana que, sacralizada, torna-se um princípio que orienta a vida humana (incluindo as instituições e a lei); (b) aplica-se essa noção à crítica política da economia, da ecologia, mas também da organização dos modos de ser, dos horizontes de plausibilidade e do desejo, e da espiritualidade; (c) ainda, compreende a crítica das inversões mítico-teológicas que fundamentam uma ética em que o mal é praticado como se fosse bom. Tal crítica se fundamenta na defesa da inocência das vítimas.

A segunda forma de uso da categoria, que não deixa de ser articulada à primeira, é como um processo de discernimento dos deuses, que julga como falso qualquer deus que exija sacrifício de vida humana ou que não reconheça o valor absoluto da vida humana secular/ profana.

Nossa hipótese é que o discernimento de deuses, desvelando os ídolos da opressão e conjurando os sortilégios do fetiche, potencializa a rebelião do sujeito rumo à conversão ecológica, na transição da maneira de ser fetichizada para uma outra em libertação, com outros valores, representações mentais, simbólicas e outra espiritualidade. Toda esta temática merece maior aprofundamento. No entanto, nos limites desta reflexão, pretendemos concluir indicando pistas de como seria possível um tipo de conversão ecológica a partir de um itinerário pedagógico. Para tal, vamos pensar não só a partir da Encíclica Laudato Si', como também considerando um depoimento pessoal do Pontífice.

\section{A conversão como itinerário pedagógico}

Se entendemos um processo educativo para a conversão como a educação para outro estilo de vida, com novos hábitos e valores, estamos pensando nas maneiras de gestar algo mais profundo que é um outro sentido 
para a vida7 como maneira de ler o mundo. Para isso, é necessário negar a antropologia do mercado, a mercantilização da dignidade humana e a liberdade pelo consumo, expressando o ateísmo frente os ídolos. Frente à aura religiosa do capitalismo, é necessário escolher: ou aderir ou ser ateu de seus fundamentos. Não se trata de afirmar que, apesar da beleza fascinante da sociedade de consumo, faremos um sacrifício em renunciar as suas benesses em nome de uma sustentabilidade ecológica.

É necessário protestar claramente: esse mundo não é bom, provoca o que há de pior na humanidade, semeia frustração e agressividade e ainda conduz o planeta à casa do desespero e do suicídio. Não se trata de um sacrifício, mas de escolher a vida possível para todos. Para tanto, não é possível apenas no âmbito da razão instrumental, mas como nos alerta Jung Mo Sung:

\begin{abstract}
Uma mudança tão radical no comportamento, nos valores e no sentido da vida não é resultado de uma exposição teórica, mas sim de um complexo processo de sedução e convencimento, que passa pela substituição de velhos símbolos e mitos tradicionais pelos novos e, principalmente, pela introdução de novos modelos do que é ser humano, pessoas que são apresentadas como portadoras desse ser que almejamos e que vão nos indicar o que desejar e fazer para nos realizarmos como seres humanos (SUNG, 2012, p.106).
\end{abstract}

A sociedade do consumo e seus valores, no sistema capitalista, tem grande poder de atração e adesão pelo processo formativo resultante de milhões de dólares investidos em propagandas e publicidade, mas também pelo mecanismo do fascínio da mercadoria, caracterizada pelo Papa Francisco (e pelos teólogos da libertação) como idolatria. A raiz deste processo é o fetichismo, que expressa uma legitimação teológica que funciona no âmbito mais profundo e integrado à existência do que a própria razão instrumental: trata-se de uma dimensão da razão mítica. Desse modo, o sistema capitalista justifica o saque e o homicídio, explora a vida humana e o ambiente, condena a desesperança, submetendo a todos às leis absolutas do mercado. Expressa uma teologia que desumaniza. Teologia da morte.

\footnotetext{
7 Jung Mo Sung tem um excelente estudo sobre a relação entre educação e o sentido da vida. Veja SUNG, 2012.
} 
Um itinerário pedagógico que seja capaz de conduzir a outro tipo de modelos de desejo fundamentais inclui a aposta de que a realização humana passe pela simplicidade, pelo cuidado e pela partilha, como crença comunitária de que é possível ser feliz no amor ao próximo. Somente com “profundo amor ao mundo e aos homens" (FREIRE, 2014, p. 110) é possível a criação e recriação da realidade.

Como ensinou Paulo Freire, "o amor é compromisso com os homens. Onde quer que estejam estes, oprimidos, o ato de amor está em comprometerse com sua causa. A causa de sua libertação" (FREIRE, 2014, p. 111). Um processo pedagógico baseado no amor, na fé e na esperança. Amor como compromisso, fé na dignidade dos seres humanos e esperança ativa de humanização.

Parece-nos que alguns elementos desse itinerário pedagógico desejado estão presentes no depoimento do próprio Papa Francisco ao contar em diferentes ocasiões o que ele chamou de sua "conversão ecológica". Entre os fatos que ele aponta em seu processo de mudança, destacamos dois: o testemunho profético dos bispos brasileiros (na Conferência de Aparecida) em seu compromisso com a defesa da Amazônia e o encontro (em Puerto Maldonado) com o rosto do indígena, com sua inteligência associada à sabedoria do bem viver. Testemunho e reconhecimento do outro. Nesse sentido, o Papa sugere articular o pensar, o sentir e o agir, atentos a diferentes tradições (pertencimento) que oferecem elementos importantes para nosso modo de viver, junto com o diálogo. Testemunho e reconhecimento do outro como diferente mobilizam não apenas informações sobre os indígenas e a crise da Amazônia, mas despertam um grau de empatia e envolvimento, que podem ser potencializados pelo diálogo entre tradições.

Penso que um bom exemplo seria o diálogo com as vítimas do sistema, mas também com os movimentos sociais que testemunham a aposta generosa de outra humanidade. Um encontro com aqueles que se rebelam contra o desastre humano e ambiental que assistimos cotidianamente.

Essa rebelião do sujeito que se sujeitiza ao negar sua desumanização permite a reorganização das apostas fundamentais da vida em direção a outros modelos, como já citado nesta reflexão, o do pobrezinho de Assis, 
indicado como paradigma de alegria e fraternidade universal. A fraternidade universal foi tema do magistério pontifício da nova Encíclica Fratelli Tutti.

Mas, na Laudato Si', o Pontífice antecipou a ideia de que o cuidado como amor civil e político enfrenta o egoísmo, a superficialidade e novas formas de crueldade originadas na competição de todos contra todos. A alegria e a paz, em São Francisco, indicam a negação da obsessão pelo consumo e o acúmulo de prazeres que impede de se alegrar com o simples, bem como questiona o culto da notoriedade, que causa desequilíbrios profundos. Francisco de Assis seria um paradigma de novos homens e novas mulheres frente o sistema vigente?

Apesar de toda a devoção popular pelo santo, seriam os cristãos e as cristãs de hoje capazes de desejar viver a simplicidade e a partilha do Evangelho como o testemunho desse grande ser humano? Talvez, somente no mesmo processo de conversão que negue o ídolo-fetiche.

\section{Considerações finais}

Argumentamos que, em nosso contexto, o fundamentalismo neoliberal avança na negação da humanidade de parte das pessoas, apostando na destruição do outro como projeto. Esse neoliberalismo radicaliza os mecanismos do capitalismo, potencializando os efeitos do desastre social e ambiental. Dissemos que esta concepção expressa uma profunda teologia da morte, que fascina inclusive parte dos cristãos e cristãs. É preciso ir além da consciência ecológica, em busca de uma conversão, no sentido de negar os fundamentos idolátricos desse sistema social e econômico.

Como diz Elza Tamez, a conversão deve ser ruptura com os condicionamentos socioeconômicos (TAMEZ, 1978, p. 291). O sistema não apenas é injusto, mas impõe a prática da injustiça como um "aspecto formativo" que a banaliza. Tal injustiça, na forma fetichizada, aparece como se fosse um bem maior, mas na verdade não passa de uma loucura racionalizada.

O espírito do fetichismo mobiliza ativamente mecanismos subjetivos de dominação, gestando o consentimento e cooperação de parte da população em seu estilo de vida de destruição e frustração. O mal não é simples vazio do 
pensar ou ausência de sentido, mas é realização de um sentido em uma racionalidade com capacidade de mobilizar vontades.

É preciso desmascarar o espírito do ídolo-fetiche que move o sistema capitalista, uma ordem social que nem sempre utiliza de linguagem religiosa explícita. Na tradição da crítica do “capitalismo como religião”, essa crítica é um processo de discernimento de deuses, que estão em luta permanente.

Tal tradição supõe uma metodologia que na América Latina permitiu a experiência histórica da Tese I benjaminiana, aquela que propõe a aliança entre o boneco e o anão, isso é, o materialismo histórico e a teologia. Proponho que esta tradição permite compreender todo o potencial crítico da pedagogia de Paulo Freire (MALAFATTI; COELHO, 2021). Essa tradição tem muito a contribuir com a tarefa de conjurar os ídolos da morte.

Um itinerário pedagógico antifetichista denuncia os critérios tacitamente aceitos de "normalidade da vida", que direcionam o modo de ser humano, bem como reflete com profundidade os modelos de desejo que, a partir da subjetividade, formam convicções, apostas e orientam os testemunhos de humanidade ${ }^{8}$. Penso que tal itinerário pode dialogar com proximidade das contribuições de Paulo Freire e partir da realidade de rebelião das vítimas, seja no reconhecimento do outro vitimado, seja a partir da revelação que nos vem do testemunho de quem luta por justiça.

Mesmo com toda a conjuntura adversa, há resistências pequenas ou grandes rebeliões que aparecem pelo mundo todo, entre aqueles que em defesa da própria vida ou em solidariedade às vítimas formulam a crítica mais radical desse projeto societário em seu engajamento antissistêmico. Essa luta entre projetos é a expressão da luta dos deuses (HINKELAMMERT, 2008).

Desse modo, é importante construir a reflexão crítica junto com movimentos radicais por justiça social e ambiental, que colaboram na gestação de ações em que a negação, indiferença, resignação sejam superados pela transmissão de uma tradição no risco do reconhecimento, testemunho, insurgência pela vida de todos.

Como contribuição, é urgente buscar na negação dos ídolos uma maneira que fomente a transição ecológica, acionando os "freios de

\footnotetext{
8 Para aprofundar esse debate, veja MIGUEZ, RIEGER e SUNG, 2012.
} 
emergência" 9 , uma interrupção messiânica, como ação conjunta na qual se gesta horizonte de plausibilidade alargado, alternativo, radicalmente humano, em que o sujeito rebelde, que até hoje foi derrotado, permaneça com esperança decidido a amar o próximo e semear ressurreição.

\section{Referências}

BENJAMIN, W. O capitalismo como religião. São Paulo: Boitempo, 2013.

COELHO, A. S. Entre acusações e perplexidades: O anticapitalismo e o Papa Francisco. Caminhos, Goiânia, v. 16, p. 63-81, 2018.

COELHO, A. S. A Idolatria e o Papa Francisco: radicalidade na crítica ao capitalismo. Estudos de Religião, v. 33, p. 203-230, 2019.

COELHO, A. S. Capitalismo como religião: Walter Benjamin e os Teólogos da Libertação. São Paulo: Editora Recriar, 2021.

CUDA, E. Trabajo y dignidad humana: un impulso ético-teológico del Papa Francisco. In: SOCIEDAD ARGENTINA DE TEOLOGÍA. ¿Dónde estás? Ser humanos en este mundo. Teología, humanidad y cosmos. Buenos Aires: Agape Libros, 2018. p. 253-268.

FRANCISCO. Carta Encíclica Laudato Si' (LS). São Paulo: Paulus/Loyola, 2015.

FRANCISCO. Catequese de 01/08/2020, Vaticano News, 2020. Disponível em: https://www.vaticannews.va/es/papa/news/2018-08/reconozcamos-erradiquemosidolos-que-nos-tienen-esclavizados.html. Acesso em: 01 mar. 2021.

FREIRE, P. Pedagogia do Oprimido. 56. ed. Rio de Janeiro: Paz e Terra, 2014.

JOÃO PAULO II. Mensagem para o Dia Mundial da Paz de 1990, Vaticano, 1989. Disponível em: http://www.vatican.va/content/john-paulii/pt/messages/peace/documents/hf_jp-ii_mes_19891208_xxiii-world-day-forpeace.html. Acesso em: 01 mar. 2021.

HIKELAMMERT, F. Hacia una crítica de la razón mítica. La Paz: Driada, 2008.

LÖWY, M. Walter Benjamin: aviso de incêndio. São Paulo: Boitempo, 2005.

\footnotetext{
${ }^{9}$ Imagem força de Walter Benjamin, na qual ele diz que talvez a revolução, ao invés de ser a locomotiva da história, seja o seu freio de emergência que para o trem. Michael Löwy destaca a importância de relacionar a crítica ao capitalismo e a crítica ecológica (LÖWY, 2019).
} 
LÖWY, M. O que é o cristianismo de libertação. São Paulo: Perseu Abramo; Expressão Popular, 2016.

LÖWY, M. Laudato Sí: uma encíclica anticapitalista. In: LÖWY, M.; BENSAÏD, D. Centelhas. São Paulo: Boitempo, 2017. p. 221-226.

LÖWY, M. A revolução é o freio de emergência: ensaios sobre Walter Benjamin. São Paulo: Autonomia Literária, 2019.

MALAFATTI, F.; COELHO, A. S. Paulo Freire e o cristianismo da libertação: contribuição do conceito de visão social de mundo. Práxis Educativa, v. 16, p. 1-16, 2021.

MIGUEZ, N.; RIEGER, J.; SUNG, J. M. Para além do Espírito do Império: novas perspectivas em política e religião. São Paulo: Paulinas, 2012.

POINSSOT, A. Face au Covid, le sursaut écologique. Mediapart, 2021. Disponível em: https://www.mediapart.fr/journal/france/270221/face-au-covid-le-sursaut-ecologique. Acesso em: 27 fev. 2021.

SUNG, J. M. Educar para reencantar a vida: Pedagogia e Espiritualidade. 3. ed. São Paulo: Editora Reflexão, 2012.

SUNG, J. M. A graça de Deus e a loucura do mundo. São Paulo: Editora Reflexão, 2015.

TAMEZ, E. La conversión como afirmación de la vida: un acercamiento bíblicoteológico In: TAMEZ, E.; TRINIDAD, S. (Ed.). Capitalismo: violência y anti-vida - la opresión de las mayorías y la domesticación de los dioses. San José: EDUCA, 1978. Tomo II, p. 285-294. 